\title{
Dissociation between Vasodilation and Leishmania Infection-enhancing Effects of Sand Fly Saliva and Maxadilan
}

\author{
Fábio Castro-Sousa, Moacir Paranhos-Silva, Ítalo Sherlock, Mariza S Paixão*, \\ Lain C Pontes-de-Carvalho/**, Washington LC dos-Santos/**/+
}

\begin{abstract}
Laboratório de Imunologia Molecular e Celular, Centro de Pesquisas Gonçalo Moniz-Fiocruz, Rua Valdemar Falcão 121, 40295-001 Salvador, BA, Brasil *Lacen-Secretaria da Saúde do Estado da Bahia, Salvador, BA, Brasil **Escola Bahiana de Medicina e Saúde Pública, Salvador, BA, Brasil
\end{abstract}

In this study, the ability of maxadilan and Lutzomyia longipalpis salivary gland lysate to enhance the infection of CBA mice by Leishmania major and of BALB/c mice by L. braziliensis was tested. No difference was observed between sizes of lesion in CBA mice infected with $\mathrm{L}$. major and treated or not with salivary gland lysate or maxadilan, although they were injected in concentrations that induced cutaneous vasodilation. Although parasites were more frequently observed in foot pads and spleens of animals treated with maxadilan than in the animals treated with salivary gland lysate or saline, the differences were small and not statistically significant. The lesions in BALB/c mice infected with $\mathrm{L}$. braziliensis and treated with maxadilan were slightly larger than in animals that received Leishmania alone. Such differences disappeared 14 weeks after infection, and were statistically significant only in one of two experiments.

Key words: Lutzomyia longipalpis saliva - maxadilan - Leishmania major - Leishmania braziliensis vasodilation

Lutzomyia longipalpis saliva has been shown to enhance Leishmania infection in mice (Titus \& Ribeiro 1988). This effect is attributed at least in part to maxadilan (Qureshi et al. 1996), a polypeptide that produces vasodilation (Lerner et al. 1991, Lerner \& Shoemaker 1992) and presents a range of immunomodulatory activities: it inhibits T-cell proliferation and delayed-type hypersensivity in mice (Qureshi et al. 1996), decreases TNF- $\alpha$ release by macrophages and increases IL- 6 and IL10 production in response to LPS, both in vitro (Soares et al. 1998) and in vivo (Bozza et al. 1998). In addition, maxadilan inhibits the intracellular killing of Leishmania by macrophages (Soares et al. 1998). In this study, we tested the ability of maxadilan and salivary gland lysates of $L$.

This work was supported by the Brazilian Ministry of Science and Technology (Brazilian National Research Council, CNPq, grant no. 521260/98-1 and Pronex). ${ }^{+}$Corresponding author. Fax: +55-71-356.2255. E-mail: wluis@cpunet.com.br

Received 14 November 2000

Accepted 16 May 2001 longipalpis, with intense vasodilation activity, to enhance the infection of CBA and BALB/c mice with L. major (MHOM/IR-173) and L. braziliensis (MHOM3456), respectively.

Groups of 6 to $18 \mathrm{CBA}$ or BALB/c mice were used in four separate experiments. Two different batches of maxadilan were used: one recombinant (provided by Dr John David, Harvard School of Medicine, USA) and one synthetic (Soares et al. 1998) (provided by Dr Richard Titus, Colorado State University, USA). As expected, each batch produced diarrhoea when injected intraperitoneally in mice and cutaneous hyperaemia when injected intradermically in rabbits. Salivary glands were isolated from L. longipalpis, and lysates prepared with these glands also produced skin hyperaemia in rabbits. The CBA and BALB/c mice were infected into the foot pads with $10^{5}$ fourth in vitropassage, stationary-phase, Leishmania promastigotes suspended in (1) phosphate-buffered saline containing $0.1 \%$ bovine serum albumin (PBS$0.1 \%$ BSA) alone, or (2) PBS- $0.1 \%$ BSA containing a half acinus of $L$. longipalpis salivary gland (only CBA mice), or (3) PBS-0.1\%BSA containing maxadilan (1, 5, 50 and $1000 \mathrm{ng}$ per injection). The total volume of injected material was $25 \mu$ l. The concentration of salivary gland lysate was 10 - 
fold higher than that necessary to cause cutaneous vasodilation (as determined by dose-response experiments in three rabbits), and the concentrations of maxadilan ranged from 2 to 2,000-fold higher than that necessary to cause cutaneous vasodilation in the rabbits treated. The viability and virulence of L. major promastigotes was confirmed by their ability to produce lesions in BALB/c mice.

No differences in the levels of circulating antiLeishmania antibodies as detected in ELISA (not shown), permanence of the parasite in the site of inoculation, or dissemination of Leishmania to spleen, liver and lung (Table), were observed between groups of CBA mice infected with L. major in the presence or absence of salivary gland lysate, after 9,14 or 21 weeks of observation. One of the batches of maxadilan caused no change in the development of $L$. major-induced lesion in CBA mice (not shown). With the other batch a slight increase in the size of the lesion was observed after the 13th week of infection in one experiment (Fig. 1). Although the group treated with maxadilan had a higher frequency of positive foot pad cultures and dissemination of parasites to the spleen (Table) and higher levels of anti-Leishmania antibodies in ELISA (not shown), these differences were not statistically significant.

There was a slight increase in lesion size of BALB/c mice infected with L. braziliensis and maxadilan, compared with the animals infected with $L$. braziliensis alone (Fig. 2). This difference, however, was small and reached statistical significancy in only one out of two experiments. In both groups of animals the lesion subsided after 14 weeks of infection.

The results described herein conflict with those of other authors (Titus \& Ribeiro 1988, Qureshi et al. 1996, Donnely et al. 1998, Mbow et al. 1998), and clearly show that the reported enhancing effect of sand fly saliva on Leishmania infection is not easily reproducible. The reason for this dis-

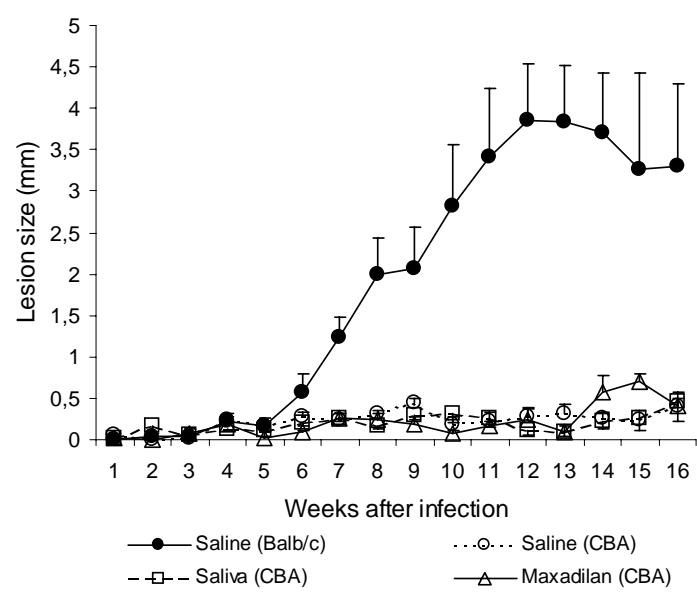

Fig. 1: effect of Lutzomya longipalpis salivary gland and maxadilan on Leishmania major infection in CBA mice. Lines represent mean \pm SEM of lesion sizes. Only a small and transient increase in lesion size was observed in the CBA group treated with maxadilan (maxadilan) after 14 days of infection, compared with the CBA group infected with $L$. major only (saline). BALB/c mice were used as a control of L. major virulence.

crepancy is not clear, but may relate to the immune status of the host, which, due to environmental conditions, may or may not respond to an immunomodulating effect of sand fly saliva. The sand fly saliva and maxadilan preparations used in this study were certainly biologically active in terms of inducing vasodilation. The data presented herein show therefore, that the induction of vasodilation by sand fly saliva does not by itself suffice to significantly enhance Leishmania infection. They are in agreement with the observations that L. longipalpis salivary gland lysates with high vasodilation activity did not enhance experimental L. chagasi infection in dogs (Paranhos-Silva et al. 1993, Paranhos-Silva et al. manusc. in prep.) and are less effective in enhancing Leishmania infec-

TABLE

Presence of parasites in the foot pad and dissemination to the internal organs of CBA mice infected with Leishmania major alone, or associated with salivary gland of Lutzomya longipalpis or maxadilan

\begin{tabular}{lcccccr}
\hline & \multicolumn{7}{c}{ Positive cultures } \\
\cline { 2 - 7 } Treatment & $\mathrm{FP}^{a}$ & $\mathrm{LN}^{b}$ & Spleen & Liver & Lung & Any organ \\
\hline Saline & $6 / 13^{c}$ & $6 / 13$ & $1 / 13$ & $0 / 13$ & $0 / 13$ & $9 / 13$ \\
Salivary gland & $4 / 13$ & $3 / 13$ & $0 / 13$ & $0 / 13$ & $0 / 13$ & $6 / 13$ \\
Maxadilan & $10 / 13$ & $5 / 13$ & $4 / 13$ & $0 / 13$ & $0 / 13$ & $11 / 13$ \\
\hline
\end{tabular}

$a$ : foot pad; $b$ : popliteo lymphonode; $c$ : cumulative number of animals with positive cultures obatined from material collected after 9,14 and 21 weeks of infection/total number of animals studied.

Statistical significance of the differences between group maxadilan vs saline (Fisher's exact probability test): any organ $\mathrm{p}=0.645 ;$ foot pad infection $\mathrm{p}=0.226$; spleen infection $\mathrm{p}=0.322$ 


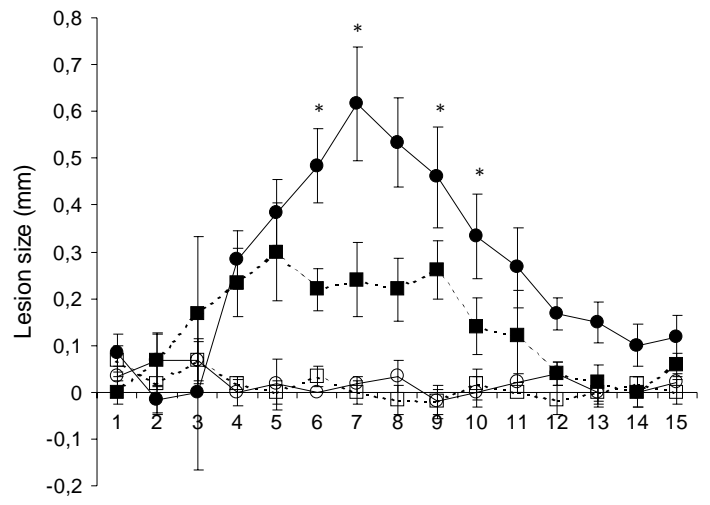

Weeks after infection

$\multimap$ Max ...

Fig. 2: maxadilan (Max) induced a small increase in the size of lesion produced by Leishmania braziliensis (Lb) in BALB/ c mice. Such increase was statistically significant only from the 6 th to the 10 th week post-infection $(* \mathrm{p}<0.05$, one way ANOVA and Student-Newman-Keuls test)

tion than salivary gland lysates with low vasodilation activity (Warburg et al. 1994). They also indicate that, since the enhancing effect of maxadilan or salivary gland lysate on Leishmania infection may be small and inconsistent, a vaccine based in immunization against sand fly saliva may not have similar efficacy in different endemic regions.

\section{ACKNOWLEDGMENTS}

To Drs John David and Richard Titus for kindly supplying maxadilan preparations.

\section{REFERENCES}

Bozza M, Soares BPM, Bozza PT, Satoskar AR, Diacovo TG, Brombacher F, Titus RG, Shoemaker CB, David JR 1998. The PACAP-type I receptor agonist maxadilan from sand fly saliva protects mice against lethal endotoxemia by a mechanism partially depen- dent on IL-10. Eur J Immunol 28: 3120-3127.

Donnelly KB, Lima HC, Titus RG 1998. Histologic characterization of experimental cutaneous leishmaniasis in mice infected with Leishmania braziliensis in the presence or absence of sand fly vector salivary gland lysate. J Parasitol 84: 97-103.

Lerner EA, Shoemaker CB 1992. Maxadilan. Cloning and functional expression of the gene encoding this potent vasodilator peptide. J Biol Chem 267: 10621066.

Lerner EA, Ribeiro JM, Nelson RJ, Lerner MR 1991. Isolation of maxadilan, a potent vasodilatory peptide from the salivary glands of the sand fly Lutzomyia longipalpis. J Biol Chem 266: 1123411236.

Mbow ML, Bleyenberg JÁ, Hall LR, Titus RG 1998. Phlebotomus papatasi sand fly salivary gland lysate down-regulates a Th1, but up-regulates a Th2, response in mice infected with Leishmania major. $J$ Immunol 161: 5571-5577

Paranhos-Silva M, dos-Santos WLC, Sherlock I, Oliveira GGS, Pontes-de-Carvalho LC 1993. Development of eosinophilia in dogs intradermically inoculated with sand fly saliva and Leishmania (Leishmania) chagasi stationary-phase promastigotes. Mem Inst Oswaldo Cruz 88: 249-251.

Qureshi AA, Asahina A, Ohnuma M, Tajima M, Granstein RD, Lerner EA 1996. Immunomodulatory properties of maxadilan, the vasodilator peptide from sand fly salivary gland extracts. Am J Trop Med Hyg 54: 665-671.

Soares MBP, Titus RG, Shoemaker CB, David JR, Bozza M 1998. The vasoactive peptide maxadilan from sand fly saliva inhibits TNF- $\alpha$ and induces IL- 6 by mouse macrophages through interaction with the Pituitary Adenylate Cyclase-Activating Polypeptide (PACAP) receptor. J Immunol 160: 1811-1816.

Titus RG, Ribeiro JM 1988. Salivary gland lysates from the sand fly Lutzomyia longipalpis enhance Leishmania infectivity. Science 239: 1306-1308.

Warburg A, Saraiva E, Lanzaro GC, Titus RG, Neva F 1994. Saliva of Lutzomyia longipalpis sibling species differs in its composition and capacity to enhance leishmaniasis. Phil Trans $R$ Soc Lond B 345: 223-230. 
1000 Sand Fly Saliva - Leishmaniasis and Vasodilation • Fábio Castro-Sousa et al. 